doubt that the protective use of tetanus antitoxin is the principal cause of the disappearance of tetanus among our wounded; there are but very few cases of it now. Sir William Osler, at the annual meeting of the Research Defence Society on June 30, rightly emphasised this point; it does not need to be emphasised for those of our readers who are medical men and have watched cases of tetanus.

After the meeting Dr. Andrew $\bar{B}$ alfour gave a demonstration of the protective treatment against typhoid, showing, with admirable ingenuity, how completely the resistance of the body to invading germs may be described in terms of human warfare. Not all men of science are skilful in the use of parables, but he is.

Some day, those of us who live long enough will be able to read the medical and surgical history of the present war. It has been taken in hand bv many writers of authority, and it will be fine reading. It will interpret to us one of the noblest records of science in practice. Interpreters of science, popularisers of science, are always useful, and the Research Defence Society has certainly done useful work by interpreting and popularising the methods and the achievements of modern physiology and pathology.

\section{FERROMAGNETISM AND THE A2 TRANSFORMATION IN IRON.}

$\mathrm{R}$ ECENT years have witnessed a remarkable conpoint $\mathrm{A}_{2}$ in iron, Moreover, whereas up to the year I904 investigations of this character were carried out chiefly by metallurgists and engineers, since that date there has been a most welcome entry of physicists and physical chemists into this field of research, who in virtue of their different training and outlook have investigated the problem from a somewhat different point of view, and, it must be granted, by more rigorously scientific methods. The paper by $\mathrm{Mr}$. Kotaro Honda, of the Imperial Tohoku University, Japan, on the nature of the Az transformation in iron, presented at the spring meeting of the Iron and Steel Institute in London, is a valuable contribution by a physicist who has made a special study of this question for a number of years.

Broadly speaking, there are three views of the nature of the $\mathrm{A}_{2}$ transformation which the author summarises in the following language:-

"(I) The transformation is an allotropic change (a to $\beta$ ) occurring at a definite temperature, or at least within a small range of temperature; (2) $\beta$-iron is not an independent phase but a solid solution of a and $\gamma$ iron; (3) the transformation is not an allotropic change but an intermolecular change taking place in the a phase within a considerable range of temperature."

The first view is historically the oldest, and is particularly identified with the late M. Osmond. It was warmly adopted by Roberts-Austen and his co-workers, and is apparently still supported by Tammann, Howe, Sauveur, Burgess, and Rosenhain, although it raises several difficulties in explaining the facts actually observed. The second view was enunciated in I912 by Benedicks, but although at first sight a promising case was made out, and it appeared to be supported by a test research published by Carpenter in I9I3, it is in conflict with many well-established facts, and has been practically abandoned. The view that $A_{2}$ is not an allotropic or phase change was first put forward by $H$. Le Chatelier, and shortly afterwards by $P$. Weiss. It numbers among its additional supporters at the present time Benedicks, Hadfield, Carpenter, Edwards, McCance, and Honda. It is the most modern view of the nature of the transformation. NO. 2384, VOL. 95]
Mr. Honda's experimental contributions to the study of the nature of the $\mathrm{A}_{2}$ critical point as revealed in his paper relate to (I) the thermal changes associated with the transformation; (2) magnetisation at high temperatures; and (3) magnetic expansions at high temperatures. With respect to the first-named they confirm what has long been known, viz., that the heat evolution on cooling, and heat absorption on heating corresponding to the $\mathrm{A} 2$ transformation take place over a wide range of temperature, at least $100^{\circ} \mathrm{C}$., although the greater part is evolved or absorbed within $30-40^{\circ} \mathrm{C}$. The complete range, however, is probably considerably more than $100^{\circ} \mathrm{C}$. A transformation extending over so wide an interval cannot properly be regarded as an instance of "one-phase allotropy." Neither is it correct to speak as Burgess and Crowe do of the temperature at which $d q / d \theta$ is a maximum, as the critical point or range. The author regards the temperature at which the heat evolution begins on cooling, or the heat absorption ends on heating, as the critical point, and uses the expression in this sense. It is also the temperature at which ferromagnetic iron becomes paramagnetic, or vice versâ.

The most important section of Honda's paper is that dealing with magnetisation at high temperatures. Many metallurgists hold the view that the magnetisation of ferromagnetic metals undergoes an abrupt change at their critical points, but this is seldom the case. In fact, the course of the temperaturemagnetisation curves changes markedly with changes of strength in the magnetising field, and Honda's experiments on pure iron, nickel, and various kinds of steels show this clearly. In a very weak field the magnetisation of iron and nickel increases with temperature at first slowly, and then very rapidly, and after reaching a sharp maximum it falls extremely quickly at the critical temperature. If the strength of the magnetising field is augmented this effect of increasing magnetisation becomes continually less. In a field of several gauss the magnetisation remains constant up to the critical point and then falls very rapidly. With further increase of field the magnetisation begins gradually to decrease from a temperature which is lower as the field is stronger, and in a field of several hundreds the magnetisation begins gradually to decrease from the room temperature. In all cases the effect of temperature on magnetisation is twofold, and the observed change of magnetisation is the sum of these two effects. The first effect is specially conspicuous in weak fields, and becomes continually less as the field is increased. It is similar to the wellknown mechanical tapping on magnetisation, which it increases, the thermal agitation playing the part of mechanical shocks. The second is a reversible effect, and always acts in diminishing magnetisation. By incessant thermal impacts the molecular magnets execute rotational vibrations about their mean orientations, and the mean magnetic effect is diminished by the vibration. It is easy to see therefore that the decrease of magnetisation increases with the amplitude of rotational vibration-i.e. with rise of temperature. In very. strong fields the first effect no longer obtains and there exists chiefly the second reversible effect of temperature.

Mr. Honda has concerned himself only with the latter, which is much the more important of the two. With respect to iron, his conclusion is as follows:"In strong fields when the irreversible thermal effect: is negligible the magnetisation begins to diminisin from the lowest temperature, the change per degree of temperature increasing at first gradually but becoming always greater as the critical temperature is approached. If the change of magnetisation indicates that an intermolecular change is taking place in the substance which at the same time manifests itself 
as the evolution or absorption of heat, then the two quantities $q$ and I must vary parallel to each other. Strictly speaking, therefore, the heat should begin to be absorbed from the lowest temperature in the case of heating, though its amount is negligibly small, except in the A2 range.'

Mr. Honda also tested the question whether the magnetic and thermal changes are really different aspects of one and the same transformation taking place in the substance. This was done by making simultaneous observations of the magnetisation and the heat evolutions or absorptions in the critical range. Both for iron and nickel it was found that the temperature of the beginning of the magnetic "transformation " on cooling, and that of its ending on heating, coincide well with the corresponding temperatures of heat evolution and absorption respectively. In other words, the critical temperature as determined magnetically agrees with that as determined thermally.

The final section of the paper contains a summary of the author's theory of ferromagnetism, according to which the shape of the molecules of a ferromagnetic substance is nearly spherical, whereas in a paramagnetic substance the molecule has an elongated or flattened form. The transformation of a ferromagnetic to a paramagnetic substance at high temperatures is explained as a consequence of the gradual deformation of the spherical molecules with rise of temperature. The paper is one which should certainly be studied by those who are interested in the $\mathrm{A} 2$ transformation, not only in pure iron but also in steels.

H. C. H. C.

\section{RECENT MARINE RESEARCHES.}

THE report of the Danish Biological Station for IgI4 contains two papers describing investigations which have been carried out at the station with a view of determining the importance of the detritus derived from the decay of Zostera and other sea-weeds as a source of food for the invertebrate bottom fauna in Danish waters. The idea was recently put forward by Dr. C. G. Joh. Petersen that in these waters this organic detritus is of much greater importance than the plankton. P. Boysen Jensen, in a paper entitled "Studies concerning the Organic Matter of the Sea Bottom," deals with the question from a chemical point of view. By determination of the quantity of pentosan in proportion to the amount of organic matter it was found that Zostera was relatively far richer in pentosan compounds than the plankton organisms. The organic matter of the sea bottom occupied an intermediate position. The author concludes that in the more sheltered waters the organic matter of the sea bottom is almcst exclusively derived from Zostera, whilst in more open waters plankton organisms are possibly of some importance.

The second paper is by cand. mag. H. Blegvad, on food and conditions of nourishment among the communities of invertebrate animals found on or in the sea bottom in Danish waters. The stomach contents of a great many animals from different localities have been studied, but unfortunately the discussion of the observations is somewhat illogical and unbalanced, so much so that it is difficult to avoid the fear that a certain amount of unconscious bias may even have crept into the observations on which the discussion is based. The author summarises his conclusions as follows :-_"Detritus forms the principal food of nearly all the invertebrate animals of the sea bottom, next in order of importance being plant food from fresh benthos plants. The value of the living phytoplankton in this connection is absolutely minimal, amounting in any case to nothing more than an indirect significance through the medium of the plankton copepods."

$$
\text { NO. } 2384 \text {, VOL. 95] }
$$

A distinct advance in the study of the question of the determination of the age of fishes by the markings on the scales has been made by $\mathrm{O}$. Winge in a paper on the value of the rings in the scales of the cod as a means of age determination, illustrated by marking experiments (Meddelelser fra Kommissionen for Havundersogelser, ser. Fiskeri, Bd. iv., No. 8). The work is based chiefly on material obtained from cod which were marked and liberated by Dr. Johs. Schmidt in the neighbourhood of the Faroes and of Iceland. Samples of the scales were taken before the cod were liberated, and again on their recapture, and the two have been compared. Considerably more than half the cod marked were recaptured, some of them after an interval of a year or more. A novel and very convincing method of recording the results of the examination of the scales has been used. The lengths of the individual sclerites on a line from the centre to the periphery of the scale have been measured, and the measurements recorded in the form of curves. These curves bring out with great clearness the difference between the summer and winter growth. The otoliths of the fish have also been studied, and the author finds that a very high degree of uniformity exists between the growth of the scales and that of the otoliths, both exhibiting growth rings by which the age of the cod can be determined.

In a paper entitled "The Salinity and Temperature of the Irish Channel and the Waters South of Ireland" (Fisheries, Ireland, Scientific Investigations, I9I3, vol. iv. [I9I4]) Mr. Donald J. Matthews gives an account of the hydrographical investigations which were carried out by the Irish Fisheries Department between February, 1903, and May, 1912. The results are based chiefly on observations made on quarterly cruises, which took place in February, May, August, and November, supplemented by temperature records and salinities obtained at more frequent intervals from lightships. An excellent series of charts and sections is given setting forth the mean surface and bottom temperatures, and salinities for each of the months February, May, August, and November, and for the whole year. The saltest water enters the Irish area between Land's End and the Scilly Islands, and this current of salt, warm water is derived from a current which has already entered the English Channel from a south-westerly direction. This salt, warm current gives rise to a peculiar cyclonic circulation in the southern entrance of the Irish Channel, which may prove to be of considerable biological importance. The author considers it possible that a layer of high salinity water, traces of which are met with off the south-west of Ireland, may be connected with the salt intermediate layer which flows out of the Mediterranean into the Atlantic, and has previously been found far to the northwards of the Straits of Gibraltar. A salinity maximum which occurs off the south-west of Ireland in May is perhaps due to this Mediterranean water. The paper concludes with a discussion of the annual temperature changes in deep water.

\section{THE FIFTIETH ANNIVERSARY OF THE WORCESTER POLYTECHNIC INSTITUTE, MASS.}

THE Worcester Polytechnic Institute celebrated the fiftieth anniversary of its foundation on June 9 , its charter having been signed on May 9, I865, by John A. Andrew, the war governor of Massachusetts. There were present representatives from eighty universities and colleges, as well as invited guests eminent as statesmen, soldiers, and engineers. The dominant note of the occasion was not so much that of rejoicing over the half-century of progress or that of greater enthusiasm for training in efficiency, but rather that 